\title{
Environmental Contamination by Echinococcus granulosus sensu lato Eggs in Relation to Slaughterhouses in Urban and Rural Areas in Tunisia
}

\author{
Raja Chaâbane-Banaoues', Myriam Oudni-M'rad ${ }^{1, *}$, Selim M'rad', Habib Mezhoud', Hamouda Babba ${ }^{1,2}$ \\ 'LP3M: Laboratoire de Parasitologie-Mycologie Médicale et Moléculaire, LR12ES08, Département de Biologie Clinique B, Faculté de Pharmacie, \\ Université de Monastir, 1 Rue Avicenne, 5000 Monastir, Tunisie; 'Laboratoire de Parasitologie, E.P.S. F. Bourguiba, 5000 Monastir, Tunisie
}

\begin{abstract}
Hydatidosis has become a real concern for health care institutions and animal rearers in Tunisia. The Tunisian endemicity is aggravated by the growing number of dogs and the difficulty of getting rid of contaminated viscera because of the lack of equipment in most slaughterhouses. Therefore, microscopic and molecular tools were applied to evaluate the role of slaughterhouses in canine infection and Echinococcus granulosus sensu lato (s. I.) egg dissemination. Exposure risk to $E$. granulosus s. I. eggs in urban and rural areas was explored in order to implant preventive and adapted control strategies. Microscopic examinations detected taeniid eggs in 152 amongst 553 fecal samples. The copro-PCR demonstrated that 138 of 152 taeniid samples analyzed were positive for E. granulosus s. I. DNA. PCR-RFLP demonstrated that all isolated samples belonged to $E$. granulosus sensu stricto (s. s.). An important environmental contamination index (25.0\%) by E. granulosus s. I. eggs was demonstrated. The average contamination index from the regions around slaughterhouses (23.3\%; 95\% Cl: 17.7-28.9\%) was in the same range as detected in areas located far from slaughterhouses (26.0\%, 95\% Cl: 21.3-30.8\%). Echinococcosis endemic areas were extended in both rural (29.9\%, 95\% Cl: 24.8-34.9\%) and urban locations (18.1\%, 95\% Cl: 13.0-22.9\%). The pathogen dissemination is related neither to the presence/absence of slaughterhouses nor to the location in urban or rural areas, but is probably influenced by human activities (home slaughtering) and behavior towards the infected viscera.
\end{abstract}

Key words: Echinococcus granulosus sensu lato, cystic echinococcosis, egg, slaughterhouse, environmental contamination, Tunisia

Hydatidosis or cystic echinococcosis is a cosmopolitan anthropozoonosis due to Echinococcus granulosus sensu lato (s. l.) metacestode [1]. Today it is recognized that E. granulosus s. l. includes 5 species, E. granulosus sensu stricto (s. s.) (genotypes G1 to G3), Echinococcus equinus (G4), Echinococcus ortleppi (G5), Echinococcus canadensis (genotypes G6 to G10), and Echinococcus felidis (lion strain) [2].

With a human surgical annual incidence (SI) averaging $12.6 / 100,000$ inhabitants, Tunisia is one of the most endemic areas amongst the Mediterranean countries [3]. In Tunisia, the canine population, essentially represented by stray and semi stray (free-roaming dogs which are fed by an owner) dogs with high adult tapeworm prevalence, is estimated at about 800,000 animals [4]. Thus, considering that the average num-

\footnotetext{
- Received 21 March 2015, revised 6 December 2015, accepted 11 January 2016.

*Corresponding author (myriam.mrad@gnet.tn)

(c) 2016, Korean Society for Parasitology and Tropical Medicine

This is an Open Access article distributed under the terms of the Creative Commons Attribution Non-Commercial License (http://creativecommons.org/licenses/by-nc/3.0) which permits unrestricted non-commercial use, distribution, and reproduction in any medium, provided the original work is properly cited.
}

ber of worms per dog is estimated at several thousands, dog feces cause a massive dissemination of the E. granulosus s. l. eggs in the environment [5]. Cystic echinococcosis is also worsened by the importance of pastoral livestock and the frequent infection of dogs by ingestion of raw infected ruminants' viscera. Illegal and home slaughtering (in small restaurants on the roadside or during cultural and religious celebrations) is common in Tunisia. In the country, dogs are used primarily to guard livestock and property. They are often fed on the discarded offal of privately slaughtered livestock. Thus, $80.0 \%$ of butchers usually have an area behind their stores devoted to slaughtering animals and in the vicinity of $52.6 \%$ of them, a remarkable presence of stray dogs was noted [6].

Moreover, $38.4 \%$ of butchers and $44.0 \%$ of the population have no idea about $E$. granulosus s. l. transmission cycle. Therefore, their behavior is inappropriate concerning the management of infected offal [6-8]. People's unawareness of the risks associated with the misuse of infected viscera increases the extension rate of hydatidosis and contributes to the public health problem in Tunisia [6]. Despite the health authorities' 
efforts to control slaughterhouses, the destruction of infected viscera is not always an easy task, mainly due to the lack of equipments. The abundance of stray dogs around and inside slaughterhouses makes these efforts useless and increases their possibility of being infected [9].

Considering aspects related to public and animal health, the aims of this study were to evaluate the role of slaughterhouses in canine infection and E. granulosus s. l. egg dissemination and to explore the differences between environmental contamination by E. granulosus s. l. eggs and exposure risk in urban and rural areas, in order to implant preventive and adapted control strategies.

A total of $553 \mathrm{dog}$ fecal samples were collected from the ground in 6 Tunisian regions: Monastir (hypoendemic area) and Sousse (mesoendemic area) situated in the North-Eastern region, Zarzis (hypoendemic region) in the South-Eastern region, and Metlaoui, Douz, and Tataouine (hypoendemic regions) in the South (Fig. 1). Isolates were collected from a portion of the feces disseminated over a soil surface of 200-400 $\mathrm{m}^{2}$. Total 219 isolates were taken from areas in the vicinity of slaughterhouses and 334 from distant areas (10-15 km). Feces were kept at least 1 week at $-80^{\circ} \mathrm{C}$ in order to inactivate the infective stages of the parasites. Helminth eggs were concentrated

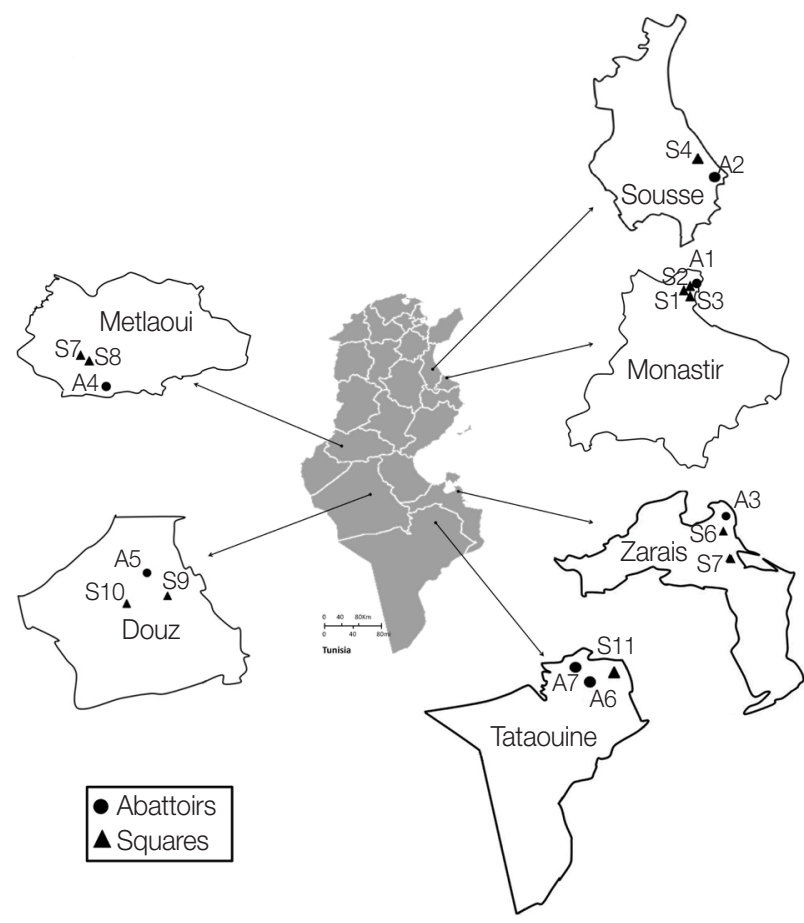

Fig. 1. Sampling collection sites in the different Tunisian studied locations. using the sucrose flotation technique with a specific gravity of 1.27 which is higher than the parasite egg densities (1.05-1.23) [10]. The presence of taeniid eggs was assessed using light microscope examinations. For positive samples, the cover-slip glasses were individually washed with $0.9 \%$ sodium chloride solution, and the elutes were stored at $-20^{\circ} \mathrm{C}$ until use.

Based on microscopic observations, taeniid eggs are morphologically indistinguishable from each other. Thus, the presence of E. granulosus s. l. eggs was ascertained by the Eg1121/1122 PCR, which permits to amplify a tandem repeat sequence, EgG1 HaeIII, specific to $E$. granulosus s. l. The presence of any of the 6 diagnostic bands (133, 300, 402, 600, 671, or 940 bp) described by Abassi et al. [11] revealed the presence of $E$. granulosus s. 1. DNA. Briefly, genomic DNA was extracted using the phenolchloroform method subsequent to an alkaline lysis using dithiothreitol (Sigma, St. Louis, Missouri, USA) and KOH (PARK Scientific Limited, Northampton, UK) and an enzymatic digestion by proteinase K (Invitrogen, Darmstadt, Germany). PCR approach was realized as previously described by Naidich et al. [12] with the primer set Eg1121a for (5'-GAATGCAAGCAGCAGATG-3') and Eg1122a rev (5'-GAGATGAGTGAGAAGGAGTG-3'). Thirtyfive cycles of denaturation $\left(95^{\circ} \mathrm{C}\right.$ for $\left.60 \mathrm{sec}\right)$, annealing $\left(55^{\circ} \mathrm{C}\right.$ for $60 \mathrm{sec})$, and extension $\left(72^{\circ} \mathrm{C}\right.$ for $\left.60 \mathrm{sec}\right)$ were carried out. PCR products were separated through $2 \%(\mathrm{w} / \mathrm{v})$ agarose gel electrophoresis. The characterization of $E$. granulosus s. l. eggs was carried out based on PCR-RFLP assay developed by Hüttner et al. [13]. PCR-positive samples from all studied regions were subjected to PCR amplification of the complete nad 1 gene sequence ( $1,071 \mathrm{bp})$, encoding the nicotinamide adenine dinucleotide dehydrogenase (NADH). PCR nad1 amplicons were then digested by HphI endonuclease as described by Hüttner et al. [13]. The genotyping of 6 isolates ( 1 sample from each studied region) was done using sequencing approach. Then, nad 1 gene amplicons were purified and sequenced using the same set of primers that have been used in the PCR-RFLP assay (Eurofins MWG, Operon, Germany).

Descriptive statistics were used to determine whether the prevalence of E. granulosus s. l. eggs varies depending on the proximity of abattoirs and the location in rural or urban areas. The contamination index (\% of dog feces positive for E. granulosus eggs) from isolates collected in different regions was analyzed with the Pearson's chi-square test, using the SPSS software version 18.0 (SPSS Inc., Chicago, Illinois, USA). The level of significance was set at $P<0.05$. The difference between the parasite egg prevalence was calculated at $95 \%$ confidence in- 
terval (95\% CI) (SPSS 18.0).

Microscopic examinations permitted detection of 152 isolates contaminated by taeniid eggs amongst 553 samples analyzed. Subsequently, the copro-PCR on these isolated taeniid eggs revealed that $90.8 \%$ of them were E. granulosus s. l. eggs. Thus, 138/152 analyzed samples presented at least 1 of the 6 bands described by Abassi et al. [11] (Fig. 2). PCR-RFLP demonstrated that all isolates were E. granulosus s. s. (Fig. 3). DNA sequencing revealed that the 6 samples analyzed were G1 genotype (GenBank accession no. KU169236 to KU169241).

Then, the contamination index was estimated at 25.0\% (Table 1). Depending on the 6 studied regions, the contamination index varied from $10.5 \%$ to $42.3 \%$. It ranged from $0.0 \%$ to $42.5 \%$ in sampling sites around slaughterhouses and from $0.0 \%$ to $46.5 \%$ in distant ones (Table 1 ). No relationship was observed between the studied regions and the contamination index distribution using the chi-square test $(P=0.26)$. The highest contamination index (46.5\%) (Table 1) was observed for the rural region of Metlaoui (south of Tunisia) which is far from slaughterhouses. Three urban (Sousse, Monastir, and Tataouine) and 1 rural (Monastir) locations were free of $E$. granulosus s. l. eggs (Table 1).

The average contamination index from the regions around slaughterhouses (23.3\%, 95\% CI: 17.7-28.9\%) was in the same range as that detected in areas located far from slaughterhouses (26.0\%, 95\% CI: 21.3-30.8\%) (Table 1). This observation was confirmed by the chi-square test attesting that the contamination index distribution was independent of the presence or absence of slaughterhouses $(P=0.51)$. Amongst the 553 feces tested, $42 / 232$ (18.1\%) and 96/321 (29.9\%) were contaminated by E. granulosus s. l. eggs in urban and rural regions, respectively. Whatever the site (near or distant from

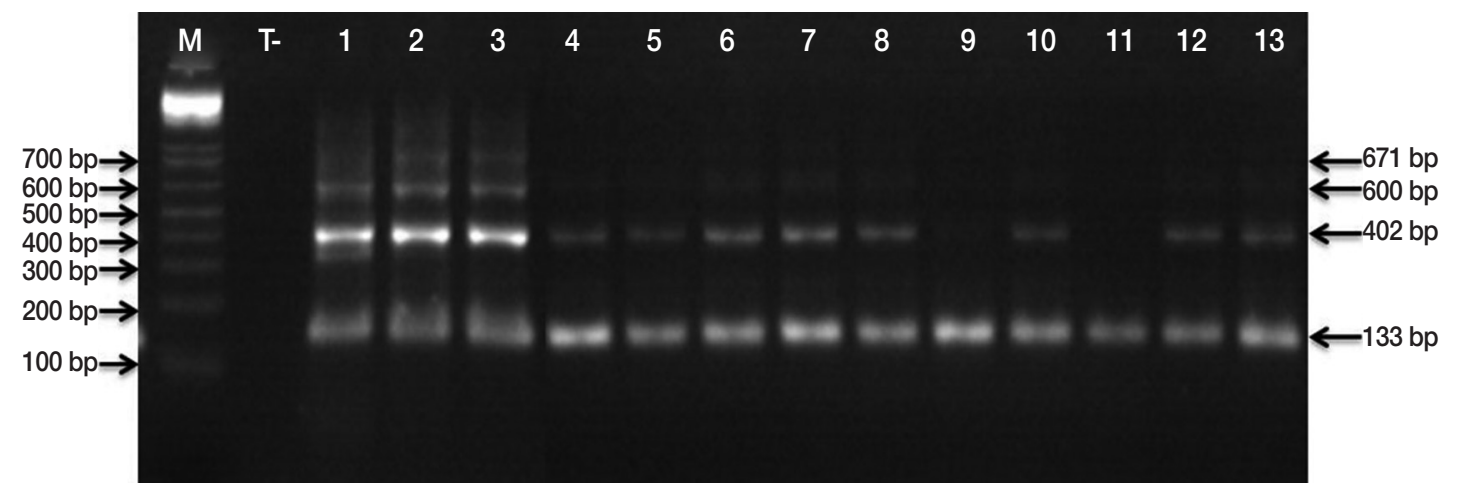

Fig. 2. PCR products of the EgG1Haell tandem repeats specific to E. granulosus sensu lato. Lane M, molecular marker 100 bp DNA ladder (Invitrogen ${ }^{\mathrm{TM}}$ ); lane T, negative control (No-DNA); lanes 1, PCR products from E. granulosus protoscolex (positive control); lanes 2-13, PCR products of isolated taeniid eggs from canine faeces.

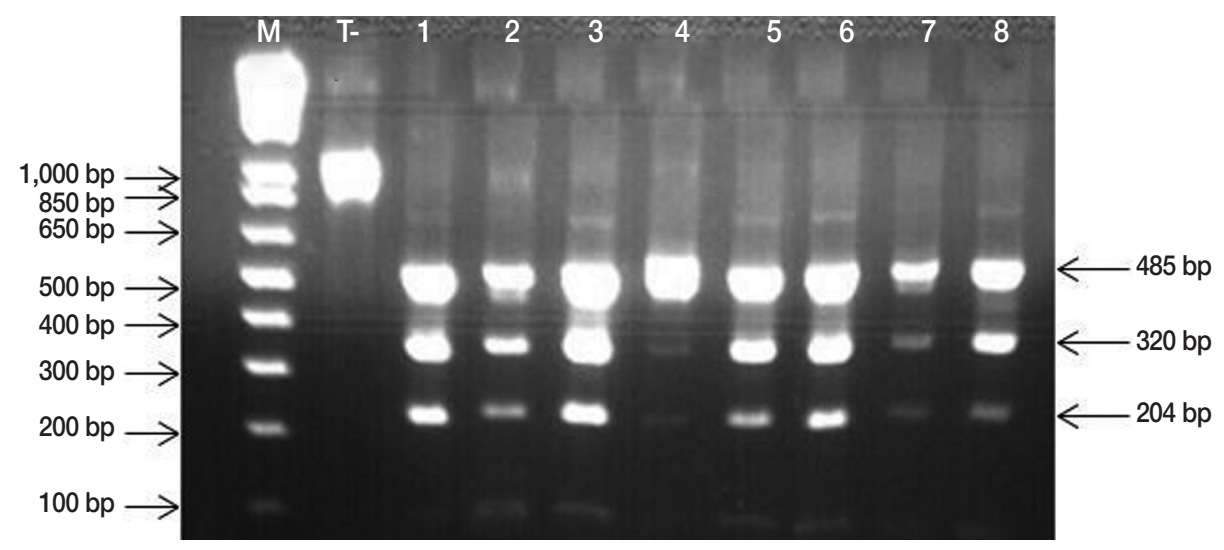

Fig. 3. PCR-RFLP banding patterns obtained by Hphl digestion of the 1,071 bp product of the nad1 gene from Echinococcus granulosus egg isolates, producing visible fragments of 485, 320, and 204 specific to Echinococcus granulosus sensu stricto. M, Molecular marker 1 kb Plus DNA Ladder (Invitrogen ${ }^{\mathrm{TM}}$ ); lanes 1, negative control (undigested amplicon); lane 2-8, E. granulosus PCR-RFLP products. 
Table 1. Echinococcus granulosus egg contamination index in fecal samples of dogs collected from urban and rural areas according to the distance between collection sites and slaughterhouses

\begin{tabular}{|c|c|c|c|c|}
\hline \multicolumn{2}{|r|}{ Regions around slaughterhouses } & \multicolumn{2}{|c|}{ Regions distant from slaughterhouses } & \multirow[b]{2}{*}{ Total (\%) } \\
\hline Site locations & $\begin{array}{l}\text { No. of } E \text {. granulosus egg-positive samples/ } \\
\text { No. of fecal samples examined (\%) }\end{array}$ & Site locations & $\begin{array}{l}\text { No. of } E \text {. granulosus egg-positive samples/ } \\
\text { No. of fecal samples examined (\%) }\end{array}$ & \\
\hline \multirow[t]{3}{*}{ Monastir $\mathrm{A} 1^{\mathrm{a}}$} & $5 / 14(35.7)$ & Monastir S1 ${ }^{\mathrm{b}}$ & $0 / 13 \quad(0.0)$ & $9 / 59(15.2)$ \\
\hline & & Monastir S2 ${ }^{\mathrm{b}}$ & $4 / 20(20.0)$ & \\
\hline & & Monastir S3 ${ }^{\mathrm{a}}$ & $0 / 12 \quad(0.0)$ & \\
\hline Sousse $A 2^{a}$ & $0 / 20 \quad(0.0)$ & Sousse S4 ${ }^{\mathrm{a}}$ & 6/37 (16.2) & $6 / 57(10.5)$ \\
\hline \multirow[t]{2}{*}{ Zarzis $A 3^{b}$} & 6/22 (27.2) & Zarzis S5 ${ }^{\mathrm{b}}$ & $4 / 23(17.4)$ & $22 / 80(27.5)$ \\
\hline & & Zarzis S6 ${ }^{b}$ & $12 / 35(34.3)$ & \\
\hline \multirow[t]{2}{*}{ Metlaoui $A 4^{\mathrm{b}}$} & $17 / 40(42.5)$ & Metlaoui S $7^{b}$ & $20 / 43(46.5)$ & $52 / 123(42.3)$ \\
\hline & & Metlaoui S8 ${ }^{b}$ & $15 / 40(37.5)$ & \\
\hline \multirow[t]{2}{*}{ Douz A5 } & 8/42 (19.0) & Douz S9b & 10/43 (23.2) & $34 / 131(26.0)$ \\
\hline & & Douz $\mathrm{S} 10^{\mathrm{a}}$ & $16 / 46(34.8)$ & \\
\hline Tataouine $A 6^{a}$ & $7 / 47(15.0)$ & Tataouine S11 ${ }^{\mathrm{a}}$ & $0 / 22 \quad(0.0)$ & 15/103 (14.6) \\
\hline Tataouine $A 7^{\mathrm{a}}$ & 8/34 (23.5) & & & \\
\hline Total & $51 / 219(23.3)$ & & 87/334 (26.0) & $138 / 553(25.0)$ \\
\hline
\end{tabular}

A, region around a slaughterhouse; $\mathrm{S}$, square distant from slaughterhouses. aUrban area.

${ }^{\text {bRural area. }}$

slaughterhouses), the samples from rural areas (29.9\%, 95\% CI: 24.8-34.9\%) were more contaminated than those from urban areas (18.1\%, 95\% CI: 13.0-22.9\%) (Table 1). However, this difference was not statistically significant $(P=0.31)$, and the distribution of E. granulosus s. l. eggs was independent of the location in rural or urban areas.

This study was conducted to assess whether there is a relationship between the distribution of E. granulosus s. l. eggs and the sites of sampling (near or far from slaughterhouses and rural vs urban areas). The fecal samples presented a contamination index by E. granulosus s. l. eggs ranging from $10.5 \%$ to $42.3 \%$ depending on the studied regions which attests of the presence of human and animal infective life stage in the environment.

Areas distant from slaughterhouses presented contamination indexes similar to those in slaughterhouse areas $(26.0 \%$ vs $23.3 \%$ ). Dog's behavior could be a key to understanding this contamination level in areas less likely to develop E. granulosus s. l. life cycle. Thus, the disease propagation model seems to be linked to dog displacement and not to the contamination source. In fact, dog feces are mainly deposited around the dog owners' houses (from 0 to $200 \mathrm{~m}$ ). This explains that wherever the dogs were infected, they often shed $E$. granulosus s. l. eggs close to their settlement [14].

Important contamination indices were detected in both rural and urban sites (29.9\% and $18.1 \%$, respectively). The distribution of E. granulosus s. l. eggs was independent of the loca- tion in rural or urban areas $(P=0.31)$. Livestock are ubiquitous all over Tunisia especially in rural areas, and about 4 million sheep female units (FU), 705,520 goat FU, 426,590 cattle FU, and 17,000 camel FU are recorded [15]. Despite modernization efforts, animal breeding remains largely traditional which promotes animal infection by E. granulosus s. l. eggs and maintains an inexhaustible source of infected viscera for canids [4]. In rural areas, the dog density is 1 for 3.0-5.5 people, and $80.0 \%$ of households own at least 1 dog [16]. Rural population is not aware of zoonotic parasites that can be carried by their pets or the parasite transmission mode. A study conducted in Tunisian rural areas showed that $36.0 \%$ of surveyed people think that human infection occurs through the consumption of meat and only $30.0 \%$ of them blame dogs for the parasite transmission. Moreover, because of the high cost and the transport difficulty, the dead carcasses of infected ruminants are often left on the pasture accessible to dogs [8].

The current study has clearly demonstrated that the isolates from the urban regions (such as Monastir, Zarzis, and Tataouine) described as hypo- or meso-endemic regions [3] were contaminated by E. granulosus s. l. eggs. The hydatidosis extension may be due to the growing number of watchdog breeds and their close contacts with humans $[1,17]$. In urban areas, the habits of Tunisian modern population have changed regarding dogs, and the dog density is around 1 dog per 16 inhabitants [16]. Indeed, a few years ago, prohibition of keeping some dogs in Muslim houses limited the contact with them. 
Therefore, dog owners need to be aware of the potential dangers caused by their pets. Some simple precautions could be adopted to reduce the dangers and the incidence of dogs with E. granulosus s. l. such as the regular use of appropriate anthelmintic treatments, not feeding them with raw offal and not allowing them to access to dead animals' carcasses [17].

Our results confirmed that, as is the case all over the world, E. granulosus s. s. (G1 genotype) is the most frequent species associated with human and animal cystic echinococcosis in Tunisia [18-20].

As a conclusion, the present study demonstrates the presence of an important contamination index of E. granulosus s. l. eggs in the environment. The pathogen dissemination is related neither to the presence or absence of slaughterhouses nor to the location in urban or rural areas, but it is probably influenced by human activities (home slaughtering) and behavior towards the infected viscera. Further studies are now required to determine the putative role of humans in the disease dissemination.

\section{ACKNOWLEDGMENTS}

This study was supported by the Ministry of Higher Education and Scientific Research, Tunisia. The authors thank Imen Hizem-Attig and Prof. Moncef Rassas for their assistance with the linguistic part of this paper. The authors are also grateful to Richard Scott for the last linguistic check of the manuscript.

\section{CONFLICT OF INTEREST}

We have no conflict of interest related to this work.

\section{REFERENCES}

1. Eckert J, Deplazes P. Biological, epidemiological, and clinical aspects of echinococcosis, a zoonosis of increasing concern. Clin Microbiol Rev 2004; 17: 107-135.

2. Romig T, Ebi D, Wassermann M. Taxonomy and molecular epidemiology of Echinococcus granulosus sensu lato. Vet Parasitol 2015; 213: 76-84.

3. Chahed MK, Bellali H, Touinsi H, Cherif R, Ben Safta Z, Essoussi M, Kilani T. Distribution of surgical hydatidosis in Tunisia, results of 2001-2005 study and trends between 1977 and 2005. Arch Inst Pasteur Tunis 2010; 87: 43-52.

4. Aoun K, Bouratbine A. Epidemiological data concerning hydatidosis in Tunisia. Med Mal Infect 2007; 37(supp1): 40-42.

5. Lahmar S, Boufana BS, Lahmar S, Inoubli S, Guadraoui M, Dhi- bi M, Bradshaw H, Craig PS. Echinococcus in the wild carnivores and stray dogs of northern Tunisia: the results of a pilot survey. Ann Trop Med Parasitol 2009; 103: 323-331.

6. Besbes M, Sellami H, Cheikhrouhou F, Makni F, Ayadi A. Clandestine slaughtering in Tunisia: investigation on the knowledge and practices of butchers concerning hydatidosis. Bull Soc Pathol Exot 2003; 96: 320-322.

7. Chahed M, Bchir A. Enquête nationale sur les connaissances, attitudes et pratiques concernant l'hydatidose. Tunis: Ministère de la santé publique, Direction de la santé et des soins de base (DSSB) (Tunisia). 1991 (in French).

8. Benabid M, Chahed MK, Nouira R, Galai Y, Bouratbine A, Aoun K. Knowledge, behaviour and implications on hydatidosis. Rev Tun Infectiol 2007; 1: 22-28.

9. Aoun K, Benabid M, Galai Y, Chahed MK, Bouratbine A. The current risk factors for hydatidosis in Tunisia. Med Trop 2009; 69: 311.

10. Dryden MW, Payne PA, Ridley R, Smith V. Comparison of common fecal flotation techniques for the recovery of parasite eggs and oocysts. Vet Ther 2005; 6: 15-28.

11. Abassi I, Branzburg A, Campos-Ponce M, Abdel Hafez SK, Raoul F, Craig PS, Hamburger J. Copro-diagnosis of Echinococcus granulosus infection in dogs by amplification of newly identified repeated DNA sequence. Am J Trop Med Hyg 2003; 69: 324-330.

12. Naidich A, McManus DP, Canova SG, Gutierrez AM, Zhang W, Guarnera EA, Rosenzvit MC. Patent and pre-patent detection of Echinococcus granulosus genotypes in the definitive host. Mol Cell Probes 2006; 20: 5-10.

13. Hüttner M, Siefert L, Mackenstedt U, Romig T. A survey of Echinococcus species in wild carnivores and livestock in East Africa. Int J Parasitol 2009; 39: 1269-1276.

14. Vaniscotte A, Raoul F, Poulle ML, Romig T, Dinkel A, Takahashi K, Guislain MH, Moss J, Tiaoying L, Wang Q, Qiu J, Craig PS, Giraudoux P. Role of dog behaviour and environmental fecal contamination in transmission of Echinococcus multilocularis in Tibetan communities. Parasitology 2011; 138: 1316-1329.

15. Ministère de l'agriculture, Direction de la production agricole. Ressources génétiques et animales en Tunisie. Presentation presented at: A symposium; 2013 Avril 14-15; Abidjan, Côte d'Ivoire. http://www.au-ibar.org/events/au-ibar/237-the-9th-conferenceof-ministers-responsible-for-livestock-in-africa?showall=\&start=1.

16. El Ghoul H. Historique et situation épidémiologique de la rage en Tunisie. Renforcement de la surveillance et des systèmes d'alerte pour la fièvre catarrhale ovine, la fièvre du Nil occidental et la rage au Maroc, en Algérie et en Tunisie. Organization of the United Nations. 2009, pp. 17. Grant no.: GCP/RAB/002/FRA.

17. Robertson ID, Irwin PJ, Lymbery AJ, Thompson RC. The role of companion animals in the emergence of parasitic zoonoses. Int J Parasitol 2000; 30: 1369-1377.

18. M'rad S, Filisetti D, Oudni M, Mekki M, Belguith M, Nouri A, Sayadi T, Lahmar S, Candolfi E, Azaiez R, Mezhoud H, Babba H. Molecular evidence of ovine (G1) and camel (G6) strains of Echinococcus granulosus in Tunisia and putative role of cattle in 
human contamination. Vet Parasitol 2005; 129: 267-272.

19. Boufana B, Lahmar S, Rebai W, Ben Safta Z, Jebabli L, Ammar A, Kachti M, Aouadi S, Craig PS. Genetic variability and haplotypes of Echinococcus isolates from Tunisia. Trans R Soc Trop Med Hyg 2014; 108: 706-714.
20. Chaâbane-Banaoues R, Oudni-M'rad M, Cabaret J, M'rad S, Mezhoud H, Babba H. Infection of dogs with Echinococcus granulosus: causes and consequences in a hyperendemic area. Parasit Vectors 2015; 8: 231. 